\title{
The Application of Augmented Reality Visual Communication in Network Teaching
}

\author{
https://doi.org/10.3991/ijet.v13i07.8780 \\ Qian Zhao \\ Jiujiang University art institute, Jiangxi, China \\ qianzhao28437@163.com
}

\begin{abstract}
In order to improve the effectiveness of online teaching, visual communication of augmented reality technology was applied. Network teaching was an auxiliary teaching form that used the network as a medium to carry out teaching information transmission. It was an extension of classroom teaching and an organic integration of information and technology and art. The visual effect of the online teaching interface directly affected the quality of teaching information delivery. Based on augmented reality technology, the research, analysis and analysis of interactive interface design content, processes and principles were carried out in terms of human-computer interaction, user experience, and visual communication. Augmented reality based visual interaction interface design methods were summarized. The results showed that visual communication based on augmented reality could provide a new form of teaching demonstration and enrich the content of classroom teaching. To sum up, this method improves the students' participation and enthusiasm, and enhances the teaching effect.
\end{abstract}

Keywords-augmented reality; interactive design; visual communication; user experience

\section{Introduction}

With the rapid development of computer technology, the interaction technologies and methods between people and computers have been iteratively enriched. HumanComputer Interaction (HCI) refers to the process of information exchange between a person and a computer using a certain dialogue language and interacting with each other to complete a certain task. In today's wave of interaction design, humancomputer interaction has begun to be focused and researched both inside and outside the industry. Augmented Reality (referred to as AR) can be regarded as one of Virtual Reality (VR). Augmented reality is the use of computers to create a virtual environment with realistic feelings of vision, hearing, force, touch and movement. And through some sensor devices, the user was immersed in the virtual environment to achieve direct natural interaction between the user and the environment. It can simulate the real scene environment, and it was a computer advanced human-computer interaction interface based on interaction and concept. Users can not only experience 
the immersive fidelity experienced in the objective physical world through the virtual reality system, but also can break through space, time, and other objective limitations, and felt experiences that cannot be experienced in the real world. Augmented reality provided a method of merging the virtual world with the real world. It was one of the important development modes of the 3D interactive interface era.

In this paper, it was during the boom of the human-computer interaction era that we attempted to use augmented reality technology as a starting point to analyze the interactive interface requirements based on augmented reality. From the aspects of human-computer interaction, user experience, visual communication, emotional design, and other aspects, the design, content, flow, and principles of the interactive interface are studied and analyzed to summarize the interactive interface design method based on augmented reality. With the use of augmented reality technology in the field of children's education as the background, the interactive interface design method is practiced and the research results are displayed. In the interface design of this discipline to explore and initiate, so that peers can learn from and common development, and continuously deepen the interface design in the computer, industrial engineering, design, art and other fields.

\section{Review}

There are many researches on augmented reality technology and user interface design at home and abroad. Yaoyuneyong and so on have found that augmented reality (AR) affects consumers' attitudes and purchase intentions [1]. Chang and so on showed that a mobile guide system, as an aid to painting appreciation, compared with audio and non-participants, AR effectively guided tourists to enhance learning and promote their mobile experience, extend the time visitors pay attention to painting [2]. Escobedo and so on said that more scholars applied augmented reality techniques to the attention management of children with autism [3]. Cheng and so on explained that Augmented Reality (AR) book learning can increase parent-child sharing of reading interactions [4]. Cai and so on showed that scholars designed and developed an augmented reality learning tool based on inquiry for the "material composition" link of junior chemistry class [5]. Students can use tags to control, combine, and interact with a three-dimensional particle model and conduct a series of exploratory experiments. However, Cabero-Almenara said that it required training and economic investment to ensure its success in the classroom [6].

\section{Method}

The interactive interface design flow based on augmented reality mainly includes: design analysis. The design analysis includes several specific steps such as user analysis, requirements analysis, task analysis, environmental analysis, and product analysis. The prototype production: the prototyping process generally includes low-fidelity prototyping and high-fidelity prototyping; debugging and molding: this section emphasizes user understandability, feasibility and control of the interface; design as- 
sessment: on the one hand, it is tested whether the system's functional flow is reasonable and whether it can meet the needs of users; on the other hand, attention is paid to the communication of information and aesthetic factors, and whether users feel comfortable when using it.

The principle of interactive interface design based on augmented reality: the "usercentered" design principle emphasizes the study of users, starting from the target user's needs and preferences to meet the users' needs as the goal. The user as the end user of the interactive interface determines the function and form of the interface.

Consistency design principles include "consistent design goals", "consistent visual appearance style" and "consistent interaction behavior". "Consistent design goals" refers to the consistent design goals of various parts of the interface system based on augmented reality, so that design ideas can be generated for the target users; "consistent visual appearance style" refers to the coordination of the visual elements in each part of the interface system, reflecting the integrity and high recognition of the interface system; "consistent interaction behavior" means that in the interaction model, different types of users trigger their corresponding behavioral events, and their interaction behavior must be consistent.

The rational design principle guarantees the rationality and clarity on the basis of system design. Any design must have both qualitative and quantitative analysis. It is a combination of rational and perceptual thinking. Efforts to reduce irrational factors are based on quantitative optimization and improvement. Design should not be affected by others. We must conduct rigorous theoretical analysis on the basis of correct and systematic facts and data to ensure the rationality of the function.

The principle of diversity design is the diversification of design factors. The emergence of more and more professional investigators and companies has brought rich data and evidence for design. However, how to obtain effective information and how to analyze design information are actually a process system that requires creative thinking and methods.

Interactivity design principles emphasize the process of interaction. This process includes two aspects: on the one hand, people's acceptance and feedback; on the other hand, the communication of the interactive devices. During the design process, the feasibility and fluency of these two interaction processes should be considered to ensure high interaction efficiency.

\section{Result}

\subsection{Interaction Interface User Analysis in Augmented Reality System}

In the human-computer interaction system, there are three factors: user factors, interactive devices, and interactive software. As the protagonist in human-computer interaction, the user factor has a dominant influence. Whether the user's approval or not directly determines the success of the interactive interface design, therefore, analyzing user behavior and awareness is a prerequisite and necessary means to design a human-centered interface. The user as the end user of the interactive interface deter- 
mines the function and form of the interface. The user analysis is an important part of the interactive interface design, including the user's needs and the user's awareness. Starting from these two aspects, the paper adopted a questionnaire survey in user research to design relevant questionnaires for augmented reality awareness and randomly selected 50 college students with different professional backgrounds to carry out surveys of user awareness to obtain user-related data. The statistics of the survey results are shown in Table 1.

Table 1. User Accreditation Awareness Questionnaire Survey Results Statistics

\begin{tabular}{|c|c|c|c|c|c|c|c|c|c|}
\hline & \multicolumn{3}{|c|}{$\begin{array}{c}\text { The degree of } \\
\text { awareness of } \\
\text { augmented reality }\end{array}$} & \multicolumn{3}{|c|}{$\begin{array}{l}\text { Acceptance of an augmented } \\
\text { reality application }\end{array}$} & \multicolumn{3}{|c|}{$\begin{array}{c}\text { Key elements of } \\
\text { augmented reality } \\
\text { application products }\end{array}$} \\
\hline & $\begin{array}{l}\text { Know } \\
\text { some- } \\
\text { thing } \\
\text { about it }\end{array}$ & $\begin{array}{c}\text { Probab } \\
\text { ly } \\
\text { know }\end{array}$ & $\begin{array}{c}\text { Neve } \\
r \\
\text { hear } \\
d\end{array}$ & $\begin{array}{c}\text { Complet } \\
e \\
\text { energy }\end{array}$ & $\begin{array}{c}\text { Selective } \\
\text { acceptan } \\
\text { ce }\end{array}$ & $\begin{array}{c}\text { Inadmissibili } \\
\text { ty }\end{array}$ & $\begin{array}{c}\text { Friend } \\
\text { ly } \\
\text { interfa } \\
\text { ce }\end{array}$ & $\begin{array}{c}\text { Tracking } \\
\text { technolo } \\
\text { gy }\end{array}$ & $\begin{array}{c}\text { New } \\
\text { hardwar } \\
e \\
\text { equipme } \\
\text { nt }\end{array}$ \\
\hline $\begin{array}{l}\text { The } \\
\text { numb } \\
\text { er of } \\
\text { peopl } \\
\text { e }\end{array}$ & 12 & 35 & 3 & 19 & 31 & 0 & 37 & 28 & 15 \\
\hline
\end{tabular}

\subsection{Augmented reality based interactive interface information design and method}

In the interactive interface based on augmented reality, a large amount of information needs to be redesigned and presented as two-dimensional or three-dimensional elements. This is also the first step to refine the interface design. The user needs to perceive the interface information through information visualization or information audition so that the user can more accurately and quickly perceive the information to be conveyed and form a high-quality interactive process.

Visual psychology is the basis and theoretical basis of information visualization. Visual psychology has an important influence on users' visual interaction. The famous "Gretar visual principle" in visual psychology has a great influence on the visual design of interactive interfaces. These principles provide visual principles for the design of interactive interfaces, including the principles of proximity, similarity, and closure.

The forms of information visualization include text, forms, graphics, images, animations, etc. The information transmission effects of different visual elements are also different. In the interactive interface based on augmented reality, these visual elements are generally used to express information in order to ensure the efficiency and accuracy of the communication. At the same time, they can provide users with more choices. 
There are usually multiple visual elements in an augmented reality-based interactive interface, and the user's vision will have a natural viewing sequence. The eye tracker can be used to discover the order in which the user performs visual browsing on the interface. How to design this visual browsing route is also an important task in the visualization of information. Reference should be made to the design principles for design. Among them, correspondence is the most direct visual element design pattern, and the corresponding common method is simulation. Another intuitive counterpart is the use of text. Using text in many situations is the most direct way to communicate with users. Second, it is a symbol. Symbolic techniques are widely used in the design industry. The symbol is more abstract than the analog design. Symbols are often accompanied by strong cultural factors, and they are a common and meaningful mapping of the development of human culture. For example, pigeons symbolize peace. When the user reads the visual information and understands the meaning of each visual element, he will integrate these fragmented contents according to a certain pattern to define the function and significance of the entire interface design. This integration of visual information is the final step in the entire information design process. What the designer wants to do is to help the user integrate the visual information of the interface accurately and quickly. Information structure is the mode of organizing information. Individual information is linked through different structures, and the organization can complete the interface of a certain function. The information structure corresponds to demand analysis, and the requirement analysis determines the basic structure of the functional interface. Voice has always been a very important way of expressing information in interactive interfaces, especially warnings and reminders. The interpretation of sound information is easier than the interpretation of visual information, mainly relying on the user's intuitive experience and life experience.

\subsection{Reality-based interaction interface interaction design and method}

Due to its special technical support, interactive interfaces based on augmented reality are also diversified in terms of interaction forms, devices, and types. Different augmented reality interaction technology types have different design methods.

Head-mounted displays: Today's augmented reality displays are still quite bulky, but developers believe they can develop eyeglass-like displays just as monitors which allow us to see computer-generated text and images. A head-mounted display (HMD) allows us to see the images and text generated by the augmented reality system.

Optical perspective: The video see-through display captures images by using a small video camera attached to the outside of the goggles to outline the wearer's surroundings. On the inside of the monitor, video images are played in real time and the images are added to the video. One problem with using a video camera is that there is a long delay in time, that is, when the viewer turns his head, there is a delay in image adjustment.

Tracking System: Hiball tracking system uses optical sensing devices and embedded LED ceilings to track movements in a small range. The biggest challenge facing augmented reality developers is the need to know where the user is located relative to 
their surroundings. There is also the problem of tracking the user's eyes and head rotation. So the tracking system must be able to recognize these movements and map the real world-related images that the user sees at any given moment.

Mobile Computing: For wearable augmented reality systems, there is not enough computing power to create three-dimensional graphics. Therefore, researchers are currently using various graphics processing capabilities that can be obtained from laptops and personal computers. Laptops are just beginning to have a graphics processor (GPU). How long does it take for a mobile graphics chip to be able to produce the smooth images seen in home video game systems?

\subsection{Visual design and method of interaction interface based on Augmented Reality}

Any interface should give the user a pleasant visual experience. The core of visual design is to convey information. It generally includes various forms of media information such as color text, images, icons, audio, video, and animation. These forms of information are combined in various forms to form visual communication in the interactive interface.

In design, color is used to attract attention, gather elements, express meanings, and increase beauty. Color can give the design more visual pleasure and beauty, and can enhance the organization and meaning of design elements. In the color design of interactive interface based on augmented reality, it should be grasped from many aspects such as the number of colors, combination, and chroma. The number of colors used should be as small as possible. In the web design, the color of the link should be based on one hue, and the other hue is complementary. Up to three are appropriate. Interface design is the same reason. In order to make the color combination beautiful, we can use the colors on the color ring (similar colors), the opposite colors on the color ring (complementary colors), the colors on the symmetric polygon corners in the color ring and the colors in nature to refine an ideal color scheme. If the main purpose of color is to attract the user's attention, then saturated colors can be fully utilized, ie, pure colors; if effects and efficiency are the primary goals, desaturation colors are utilized. The role of color psychology makes people have different associations and emotions for different color interfaces. For example, desaturation, bright colors will make people feel friendly and professional, saturated colors will make people feel interesting and passionate. In color design, designers need to grasp the color psychology, use the colors to create the interface atmosphere, and at the same time efficiently distinguish and highlight different information.

In the interactive interface, the user's eye movement can be decomposed into two kinds in the course of reading text: one is a fast movement, also called a glance; the other is an intermittent pause in a place of interest, also known as gaze. Visual cognition often occurs during the gaze process rather than the glance process. When a user encounters a text containing a new word, a new word, or a long ten-day text, the gaze time will become longer, and the unintelligible text will be revisited by scanning backwards. This should be avoided in the design of 
the interactive interface. In the process of gaze, the user first recognizes the shape of letters, words, or characters and then associates them with the meaning. Therefore, the wording and layout of the interactive interface design need designers to think carefully, so that the user can quickly and correctly understand the meaning of the text. In interactive interface design, to allow users to naturally and easily carry out text interactions, the wording and the readability and legibility of text on the layout are important criteria for judgment.

The readability of text, as the name implies, means that the user can understand the text information. The legibility of text is an important factor in text interaction in the interactive interface. To improve the legibility of the interface, attention needs to be paid to the rhythm and rhythm of the text arrangement, the change and unity of the text form, the contrast and harmony of the text volume, the balanced design of the collocation and emphasis of the text makes the text beautiful and improves the efficiency of user interaction in the interactive interface.

When users face multiple elements of a static interface, they will be equally divided among them. If an element suddenly changes to a dynamic element, that is, it moves, the user will turn all attention to this dynamic element after one-fifth of a second. The common form of dynamic interface is animation. Animation is a simulation and highly generalization of the movement and change process of things. It has a strong visual impact. The important principles of animation design are similar to the principle of "consistency" in the principles of interactive interface design. The expression of animation should be appropriate, and the mode of representation should be just right. A dynamic interface that is entirely animated also distracts the user and creates irritation.

\subsection{Bare reality based interactive interface emotion design and method}

The main goal of the interactive interface design is to be able to cause users to respond positively, make the user feel relaxed, comfortable, and can enjoy from the interactive process. Emotional design focuses on the user's emotions and feedback. It is of great significance for enhancing the interactivity of the interactive interface. An excellent interactive interface design can often encourage users to learn, act, play, interact and inspire creativity.

Practicality and usability are also important, but if there is no fun and joy, excitement and joy, anxiety and anger, fear and anger, then our life is incomplete. Anatomy of "affective" emotion design refers to the user's emotional response. The goal of emotional design is divided into three levels: instinctual level design, behavioral level design, and reflection level design. The designer can simply understand what he sees, uses, and thinks of. Of course, it is not necessarily accurate.

The level of instinctual design is the visual design of the product. The basic principle is derived from human instincts. If the visual design meets the instinctual level of thinking, then it is easier to be accepted and liked; the behavioral level design is the function realization of the product. Using the product is a series of operations. Whether the user likes the key lies in two things: Can he accomplish 
the task efficiently? Is it a fun operating experience? Excellent behavior design is reflected in four aspects: function, easy-to-understand, usability, and physical perception; the design of the level of reflection is related to the significance of the product, user awareness, and it is affected by the environment, etc., and will be more complicated and changeable. This level, in fact, is related to the user's longterm experience and needs to establish the long-term value of the brand or product. Only by establishing emotional bonds between products, services, and users, and through interactions that affect self-image, satisfaction, and memory, can we develop brand awareness, foster loyalty to brands, and brands become emotional representatives or carrier. At this level, whether the user likes the product is not related to the intrinsic value of the product, but whether the emotional bond connecting the user and the product is established.

\subsection{Based on enhancing children's educational software interface design content and process}

The "Interactive with Buchih" interactive interface design content mainly includes four parts: the startup interface, the selection interface, the dancing interface, and the scoring interface.

Just like a CD's front cover and back cover, it will display record information such as album name, artist name, artist information, record company information, and so on. The startup interface is the first impression of the product to the user, allowing the child and the parents to see the main functional orientation and interface style of "dancing with Buchi". Products as a series of "Bodgeland" products are placed in major environmental areas such as children's book stores and children's educational displays through screen displays. How to quickly attract children and parents' attention and start interaction is the primary function and task of the startup interface.

At the same time, the startup interface is also a welcome interface for the "dancing with the Buchier" interactive software. In combination with the augmented reality action recognition technology, the child determines the start of interaction by placing the position of the avatar in a designated area, taking into account the environmental factors and children's ergonomics, reasonably design the area and coordinate of the identification area and debug the interactive equipment - the position of the display screen becomes a prerequisite for the smooth progress of the interaction process.

After entering the startup interface, it is the selection interface that is presented to the child. In this interface, children can learn more about "Buccio" and select interactive playmates by moving their body positions. In the project, the protagonists of the "Buckie Paradise" will present four adorable anthropomorphic playmates: the lion cub, the monkey, the panda, and the squirrel. When the child is standing in the position corresponding to the playmate, the residence time will be used as the criterion for selection. This is also a feature that takes into account the child's mobility during the actual interaction, and allows the child to choose again. In the interactive design of the selection interface, special attention should 
be paid to the principle of "allowing users to make mistakes" to guide children to quickly understand and make their own choices.

The dancing interface is also the main interface of the entire interactive software "to dance with Buchi". In this main interface, the real environment mapped by the camera is the "stage" or interactive background, and the 3D virtual playmates dance with the children in the screen display. Children can do entertaining learning by imitating their dance. The whole process is easy and fun. The novelty effect of augmented reality brought about by the combination of reality and reality will greatly stimulate children's curiosity and interest in the game.

In addition, in order to improve the children's learning efficiency and encourage children to correctly imitate, the dancing interface will also set bonus icons to randomly appear during the dancing process, and the icon position will be set within the reach of both hands according to the standard dance movements. If the children and the virtual playmates basically match the dance movements, they can easily touch the icons. This can also help the children imitate the dance as much as possible through the "reward coin" mode in the game and add fun to the interaction. Bonus icons are set according to the dance time.

After the dance is over, it will automatically enter the scoring interface. In this interface, children will be judged according to the small icons of the rewards they receive during the dance, and the corresponding evaluation will be given. The children will be encouraged to interact again and learn again. This is to satisfy children's learning psychology.

Another function of the scoring interface is to display random screen shots of children during the interactive dance process, allowing children and parents to review the effects and fun of the interactive process.

FIG. 1 is a schematic diagram of an interface design process for children's educational software based on augmented reality.

\subsection{Design framework and model of children's educational software interaction interface based on augmented reality}

According to the design process, through the analysis of children's users, needs analysis, and interviews with some children and parents, the requirements of the interactive interface are determined. The interface design content is clearly defined, and the low-fidelity prototype is designed in accordance with the design principles. This is a draft of the interface design, as shown in Figure 2, 3, 4, 5, and 6. 


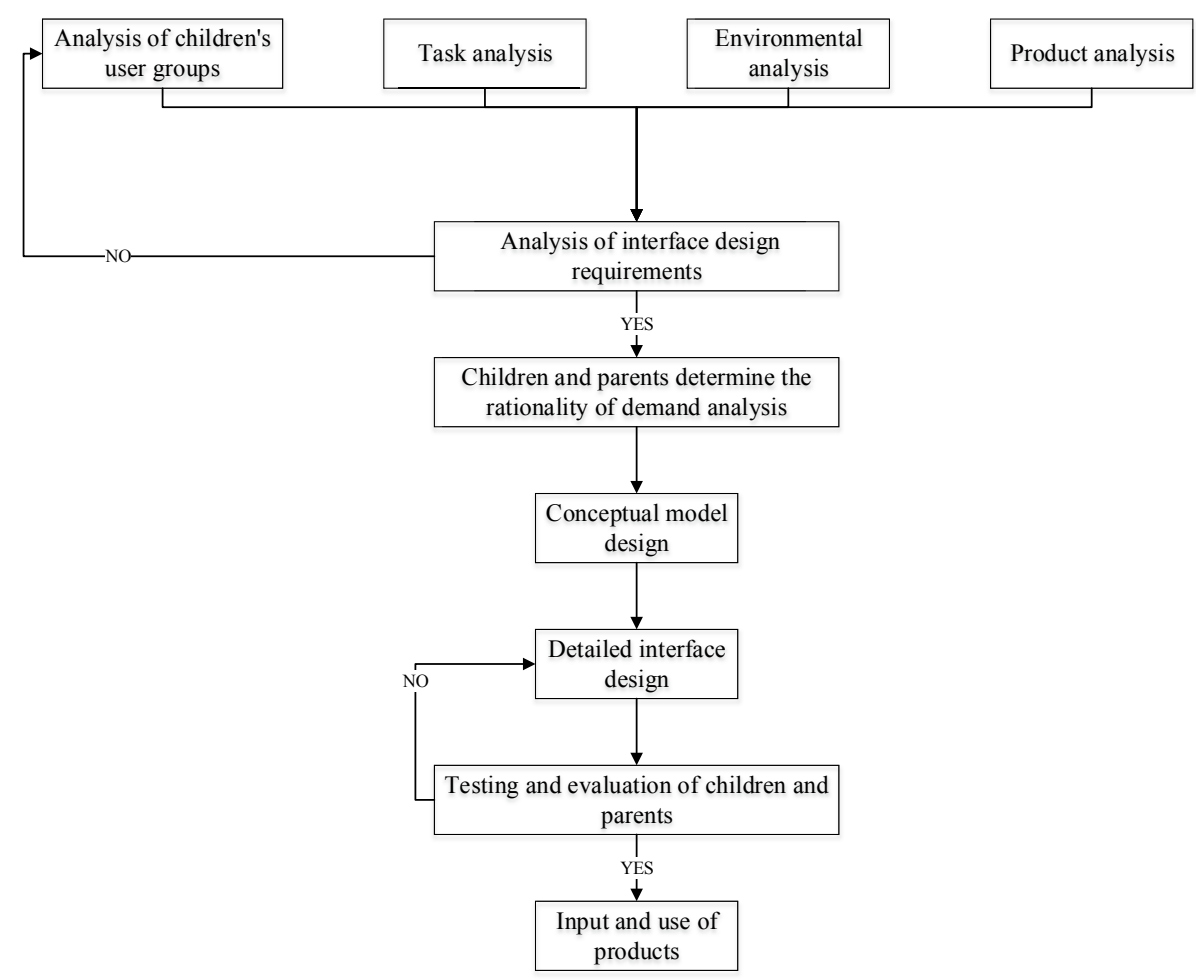

Fig. 1. Schematic diagram of an interface design process for children's educational software based on augmented reality.

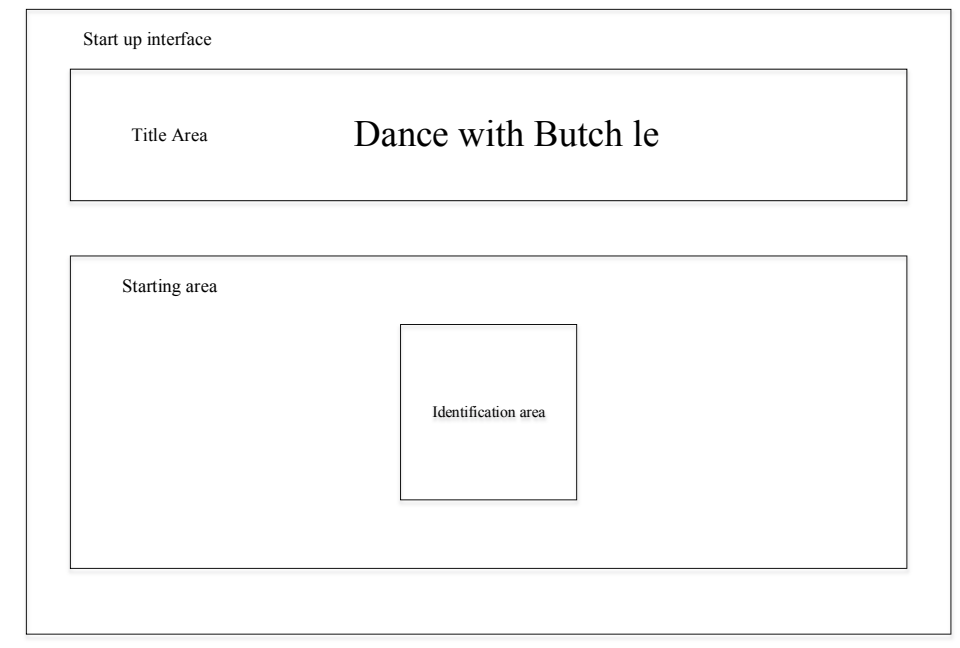

Fig. 2. Children's educational software interactive start up interface low-fidelity prototype diagram based on augmented reality 
Paper-The Application of Augmented Reality Visual Communication in Network Teaching

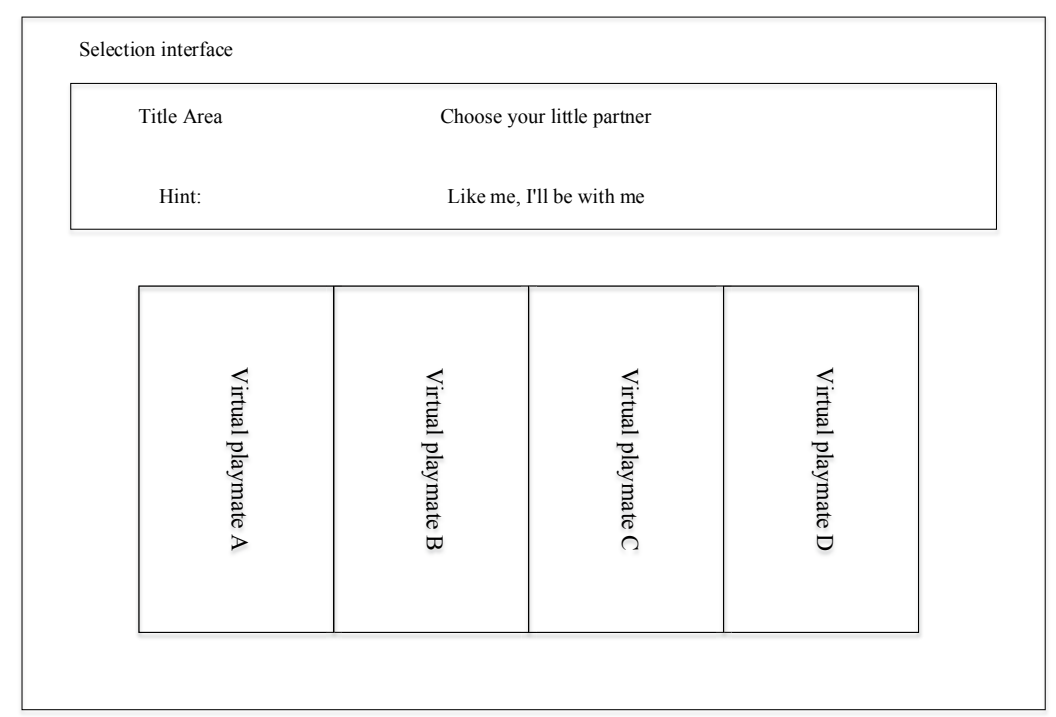

Fig. 3. Schematic diagram of interaction design interface for children education software based on augmented reality.

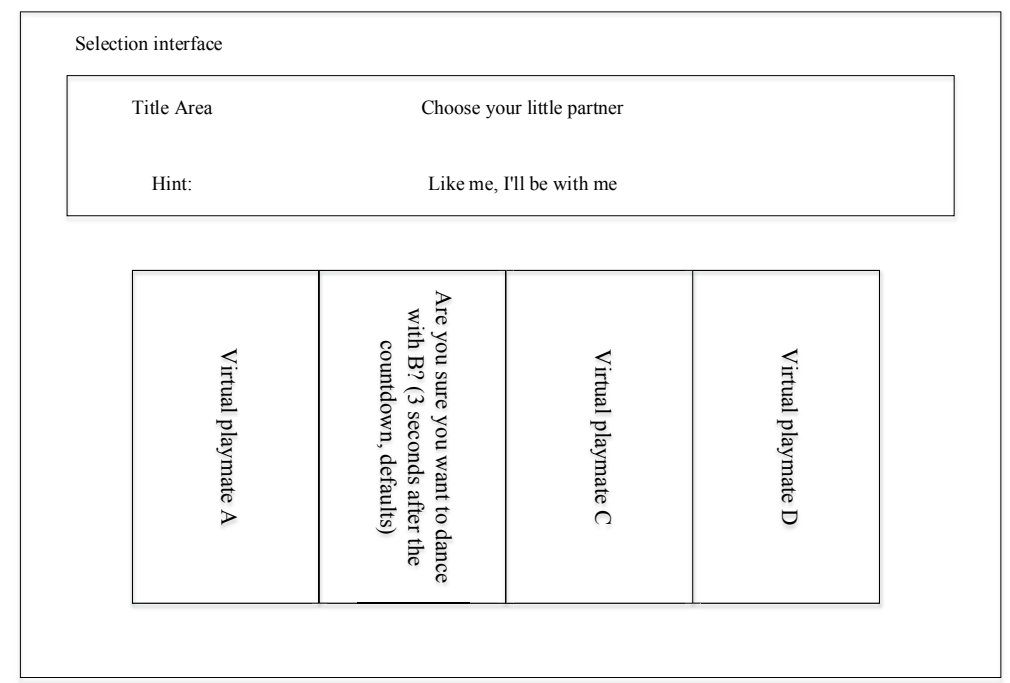

Fig. 4. Schematic diagram of interaction design interface for children education software based on augmented reality. 


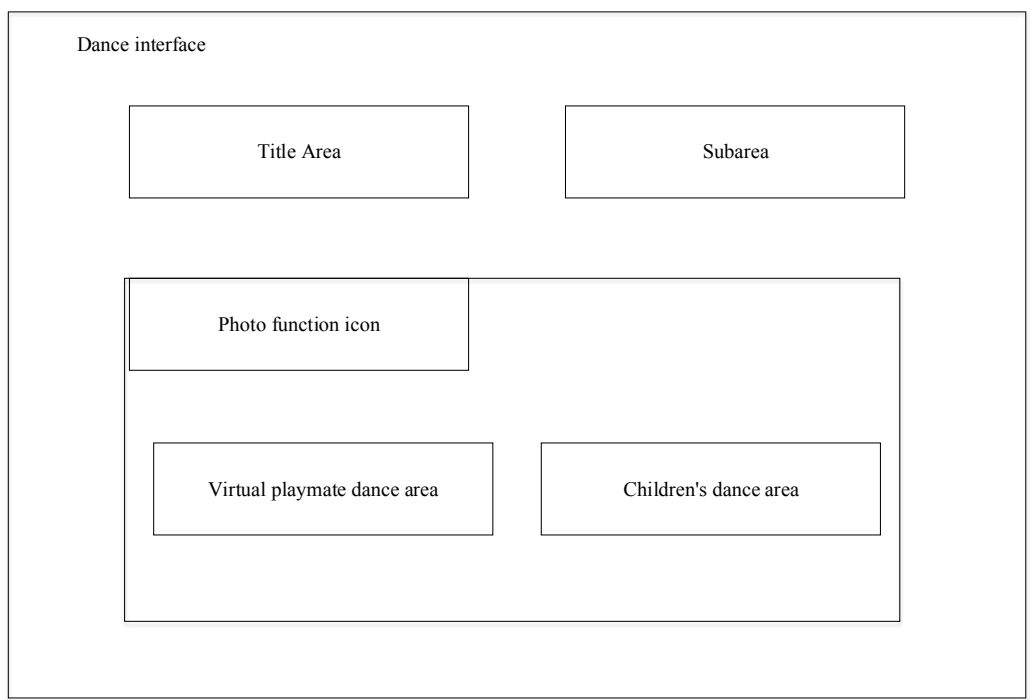

Fig. 5. Schematic diagram of interactive dance interface design process for children's educational software based on augmented reality.

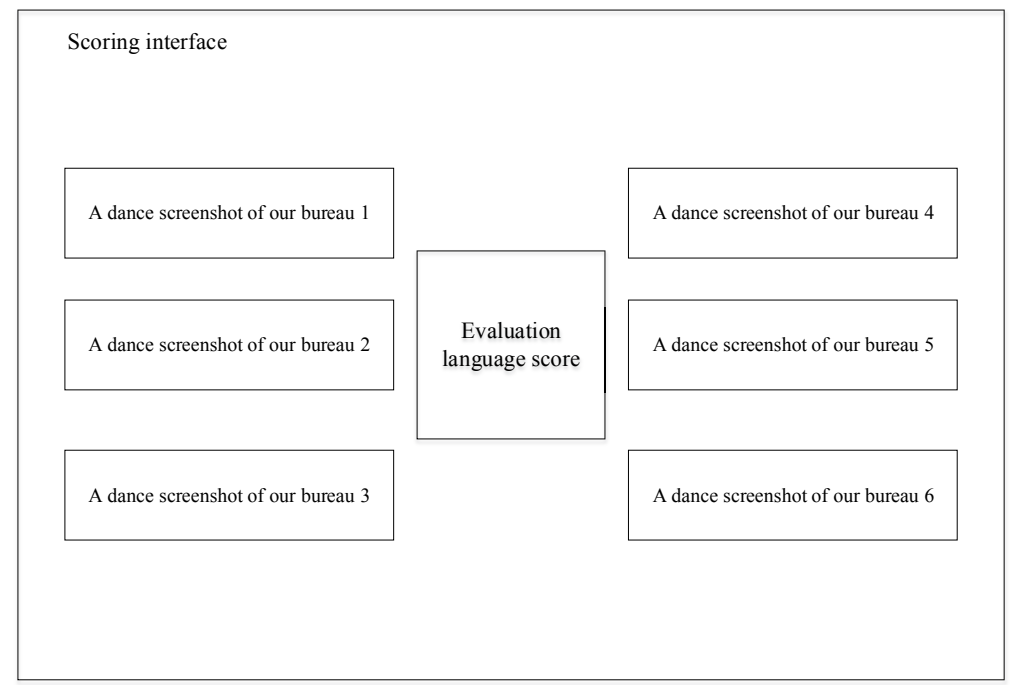

Fig. 6. Schematic diagram of interactive scoring interface design process for children education software based on augmented reality.

With the low-fidelity prototype design, the visual part of the interface was designed in detail according to the visual element design method in the interactive interface design, resulting in a draft, as shown in Figure 7. 

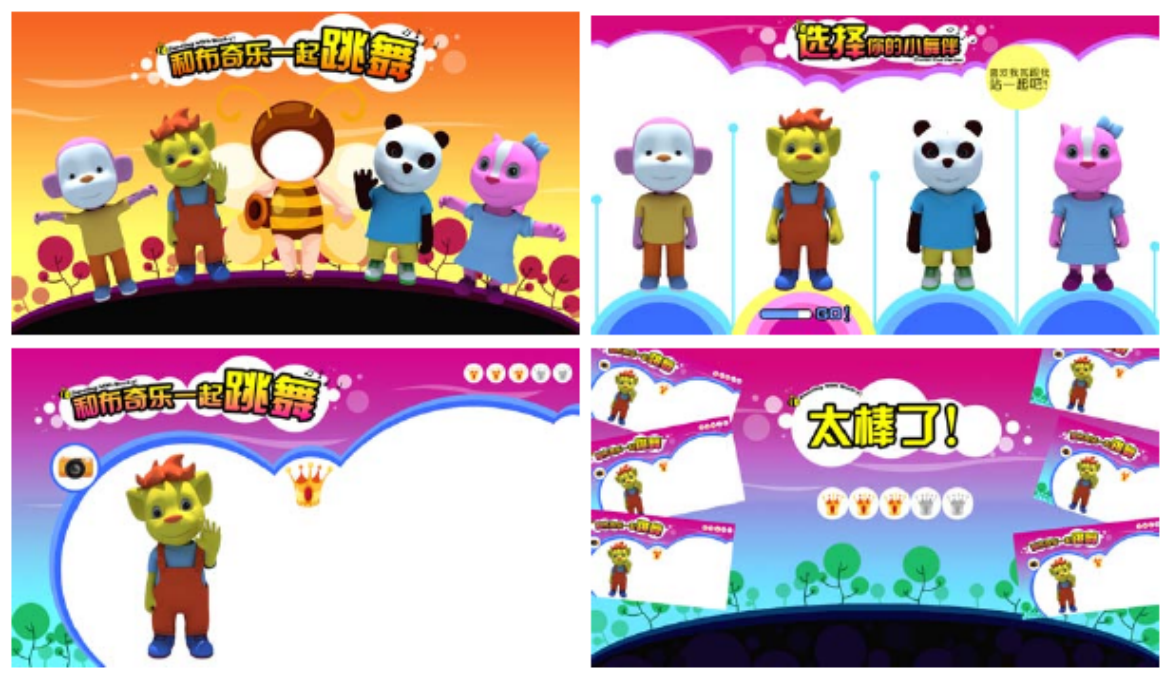

Fig. 7. Children's educational software interactive interface based on augmented reality

\subsection{A summary of practice design of interactive interface for children's educational software based on augmented reality}

Based on the application of augmented reality technology in the field of children's education, we designed the interface of the "Budge dancing together" interactive software in the "Buchee Paradise" project of the Children's Development Center of the FLTRP (Foreign Language Teaching and Research Press), and practiced the interactive interface design in this article. And it also achieved a good interactive effect and the user's positive evaluation, which shows the feasibility of the design method. As an emerging technology, augmented reality technology has its special properties and design methods in the design of interactive interface design. The concept of "user-centered" runs through the design principles, processes, and methods, improving the usability and user satisfaction of the results.

\section{Conclusion}

With the development of information technology and the maturity of humancomputer interaction technology, the social division of labor is further clarified and the design of interactive interfaces has grown into an independent industry. The author believes that this is a watershed for traditional interface design and interactive interface design. This article expounds the concept of interactive interface based on augmented reality, analyzes its prominent features, summarizes the process and principles of interactive interface design, and practices the feasibility and value of the design method. Interaction interface design is a new and complex research field. The research of this paper is only the tip of the iceberg of interactive interface design. How to analyze the theoretical characteristics of interactive interface design clearly, 
understand thoroughly, and practice in large quantities depends on the unremitting efforts of colleagues.

\section{References}

[1] Yaoyuneyong, G., Foster, J. K., \& Flynn, L. R. (2014). Factors impacting the efficacy of augmented reality virtual dressing room technology as a tool for online visual merchandising. Journal of Global Fashion Marketing, 5(4): 283-296. https://doi.org/10.1080/20932 685.2014.926129

[2] Chang, K. E., Chang, C. T., Hou, H. T., Sung, Y. T., Chao, H. L., \& Lee, C. M. (2014). Development and behavioral pattern analysis of a mobile guide system with augmented reality for painting appreciation instruction in an art museum. Computers \& Education, 71(1): 185-197.

[3] Escobedo, L., Tentori, M., Quintana, E., Favela, J., \& Garciarosas, D. (2014). Using augmented reality to help children with autism stay focused. IEEE Pervasive Computing, 13(1): 38-46. https://doi.org/10.1109/MPRV.2014.19

[4] Cheng, K. H., \& Tsai, C. C. (2014). Children and parents' reading of an augmented reality picture book: analyses of behavioral patterns and cognitive attainment. Computers \& Education, 72(C): 302-312. https://doi.org/10.1016/j.compedu.2013.12.003

[5] Cai, S., Wang, X., \& Chiang, F. K. (2014). A case study of augmented reality simulation system application in a chemistry course. Computers in Human Behavior, 37(37): 31-40. https://doi.org/10.1016/j.chb.2014.04.018

[6] Cabero-Almenara, J., Vázquez-Cano, E., \& López-Meneses, E. (2018). Use of augmented reality technology as a didactic resource in university teaching. Formacion Universitaria, 11(1): 25-34. https://doi.org/10.4067/S0718-50062018000100025

\section{$7 \quad$ Author}

Qian Zhao is with Jiujiang University art institute, Jiangxi, 332000, China.

Article submitted 25 April 2018. Final acceptance 07 May 2018. Final version published as submitted by the author. 